\title{
Aspectos socioeconômicos e culturais de benzedores que utilizam plantas medicinais em suas práticas populares de cura, no Município de Guatambu, Santa Catarina
}

\author{
Socioeconomic and cultural aspects of healers who use medicinal plants in their popular healing \\ practices in the City of Guatambu, Santa Catarina \\ Aspectos socioeconómicos y culturales de los curanderos que utilizan plantas medicinales en sus \\ prácticas curativas populares en la Ciudad de Guatambu, Santa Catarina
}

Recebido: 07/10/2021 | Revisado: 14/10/2021 | Aceito: 16/10/2021 | Publicado: 18/10/2021

\author{
Camila Mabel Sganzerla \\ ORCID: https://orcid.org/0000-0002-4808-1319 \\ Universidade Comunitária da Região de Chapecó, Brasil \\ E-mail: camilamabel.s@ hotmail.com \\ Ana Júlia Predebon \\ ORCID: https://orcid.org/0000-0001-8628-0821 \\ Universidade Comunitária da Região de Chapecó, Brasil \\ E-mail: predebon.ana@unochapeco.edu.br \\ Jaqueline Janaine Veloso \\ ORCID: https://orcid.org/0000-0002-3853-9402 \\ Universidade Comunitária da Região de Chapecó, Brasil \\ E-mail: jaquelineveloso27@gmail.com \\ Lincon Bordignon Somensi \\ ORCID: https://orcid.org/0000-0002-8435-7124 \\ Universidade do Vale do Rio do Peixe, Brasil \\ E-mail: somensilb@gmail.com \\ Junir Antonio Lutinski \\ ORCID: https://orcid.org/0000-0003-0149-5415 \\ Universidade Comunitária da Região de Chapecó, Brasil \\ E-mail: junir@unochapeco.edu.br \\ Walter Antônio Roman Junior \\ ORCID: https://orcid.org/0000-0001-8363-8795 \\ Universidade Comunitária da Região de Chapecó, Brasil \\ E-mail: romanwa@unochapeco.edu.br
}

\begin{abstract}
Resumo
A medicina popular é a soma do conhecimento, das habilidades e práticas de cura de diferentes culturas. Nesse contexto, este estudo visou identificar os benzedores que utilizam plantas medicinais em suas práticas, bem como, realizar um levantamento socioeconômico destes agentes populares de cura, no município de Guatambu (SC). A pesquisa foi realizada no perímetro rural e urbano, utilizando a técnica de snowball sampling (bola de neve), associada a um questionário semiestruturado. Como resultados, os agentes populares de cura são em sua maioria mulheres (72\%), com atividades na agricultura (47\%) e com idade de 60 a 71 anos (51\%). A escolaridade apontou para o ensino fundamental $(53 \%)$ e a constituição familiar com o cônjuge $(75 \%)$. Foi observada a importância da religiosidade nestas atividades, destacada principalmente pela fé entre quem pratica, e quem recebe o benzimento. A prática do benzimento na maioria das vezes é aplicada para o tratamento de rendiduras/machucaduras (dores musculares) sendo aplicados geralmente, de forma gratuita. Os preparados à base de plantas medicinais são comumente produzidos por decocção, infusão ou xaropes, e podem auxiliam na renda familiar. Foi verificado ainda, a preocupação dos agentes em não ter a quem transmitir seus ensinamentos ao final da vida, devido ao desinteresse dos mais jovens. Esta investigação, contribui na valorização da cultura imaterial e do saber popular do município, bem como, na compreensão da relação dos indivíduos com o meio ambiente e sua importância na conservação da biodiversidade.
\end{abstract}

Palavras-chave: Curandores; Medicina popular; Resgate cultural.

\section{Abstract}

Folk medicine is the total of knowledge, skills, and healing practices from different cultures. In this context, this study aimed to identify the healers who use medicinal plants in their practices as well as carry out a socio-economic survey of these popular healing agents in the city of Guatambu (SC, Brazil). The survey was carried out in the rural and urban perimeter, using the snowball sampling technique, associated with a semi-structured questionnaire. As a result, the popular healing agents are mostly women (72\%), with activities in agriculture (47\%) and aged between 60 and 71 
years $(51 \%)$. Schooling pointed to elementary school $(53 \%)$ and family constitution with the spouse $(75 \%)$. The importance of religiosity in these activities was observed, mainly highlighted by the faith between those who practice and those who receive the blessing. The practice of blessing most of the time is applied to the treatment of muscle aches being applied generally, free of charge. Preparations based on medicinal plants are commonly produced by decoction, infusion, or syrups and help with family income. It was also verified the concern of the agents is not having someone to transmit their teachings at the end of life, due to the lack of interest of the younger people. This investigation contributes to the appreciation of the intangible culture and popular knowledge of the municipality, as well as to the understanding of the relationship of individuals with the environment and its importance in the conservation of biodiversity.

Keywords: Healers; Folk medicine; Cultural rescue.

\section{Resumen}

La medicina popular es la suma total de conocimientos, habilidades y prácticas curativas de diferentes culturas. En este contexto, este estudio tuvo como objetivo identificar a los curanderos que utilizan plantas medicinales en sus prácticas así como realizar un relevamiento socioeconómico de estos populares agentes curativos en la ciudad de Guatambu (SC, Brazil). La encuesta se realizó en el perímetro rural y urbano, utilizando la técnica de muestreo de bola de nieve (bola de nieve), asociada a un cuestionario semiestructurado. Como resultado, los agentes curativos populares son en su mayoría mujeres ( $72 \%)$, con actividades en la agricultura (47\%) y con edades comprendidas entre los 60 y 71 años $(51 \%)$. La escolaridad apuntaba a la escuela primaria (53\%) y la constitución familiar con el cónyuge (75\%). Se observó la importancia de la religiosidad en estas actividades, destacada principalmente por la fe entre quienes practican y quienes reciben la bendición. La práctica de bendecir la mayoría de las veces se aplica al tratamiento de contusiones musculares que se aplican generalmente, de forma gratuita. Las preparaciones a base de plantas medicinales se producen comúnmente por decocción, infusión o jarabes y ayudan con los ingresos familiares. También se constató la preocupación de los agentes por no contar con quien trasmitir sus enseñanzas al final de la vida, debido al desinterés de los más jóvenes. Esta investigación contribuye a la apreciación de la cultura intangible y el conocimiento popular del municipio, así como a la comprensión de la relación de los individuos con el medio ambiente y su importancia en la conservación de la biodiversidad.

Palabras clave: Curanderos; Medicina popular; Rescate cultural.

\section{Introdução}

Ao longo da história, as pessoas interagiram com os recursos naturais de várias maneiras. Essas interações diretas ou indiretas resultaram em relações históricas que são extremamente importantes para sociedades humanas (Albuquerque et al., 2013; Albuquerque, Alves, De Lucena, 2014). De fato, em todas as épocas da humanidade há algum tipo de registro sobre o sofrimento de pessoas que são acometidas por enfermidades corporais ou psíquicas, e sua concomitante prática curativa, seja ela espiritual, por meio de rituais, ou corporal, por meio de práticas de cura utilizando elementos da natureza e intermediados por representantes de divindades (Gewehr et al., 2017). O uso de remédios à base de ervas por exemplo, remonta às tribos primitivas em que as mulheres se encarregavam de preparações caseiras à base plantas, para utilizá-las na cura das doenças. Com o passar do tempo, estabeleceram-se papéis sociais específicos para os membros da comunidade em que viviam, e uma dessas atribuições, foi o de curandeiro ou benzedor. Este agente dispunha de um amplo repertório de conhecimento tradicional e de preparados naturais, que guardava com zelo, transmitindo-o seletivamente, a iniciados bem-preparados (Simon, 2001; França et al., 2007).

No contexto brasileiro, há registros de práticas populares de cura desde o período colonial, no século XVII. Estas atividades eram realizadas por imigrantes europeus e contavam com a influência dos ritos e signos de culturas indígenas e africanas. Partem de conhecimentos sobre curas por meio de orações, rituais e ervas medicinais assim como, a utilização de outros artefatos extraídos da natureza (Gewehr et al., 2017; Marin; Scorsolini-Comin, 2017).

Atualmente, os benzedores conhecidos também como agentes populares de cura, são vistos como alguém possuidor de um conhecimento capaz de restaurar o equilíbrio e restituir a saúde. Como de conhecimento, o desenvolvimento de suas práticas provém de um processo ao longo do tempo, permeado por transformações sociais, psicológicas, emocionais e espirituais, inclusive no que se refere ao reconhecimento público de sua comunidade local. Assim, este exercício tem como 
base, um saber popular acumulado pela experiência que é na maioria das vezes, repassado pela oralidade entre as gerações (Gelesk, 2014; Lima et al., 2017; Mendes; Cavas, 2017).

Os trabalhos científicos, bem como, a socialização dos resultados destas pesquisas, têm contribuído para a recuperação de saberes, práticas e para o autoconhecimento sociocultural dessas comunidades tradicionais. Essas investigações têm buscado compreender, dentre outros aspectos, como são utilizadas as plantas por grupos étnicos. Neste sentido, tem sido desenvolvidas abordagens em etnobotânica, etnomedicina e etnofarmacologia (Chagas et al., 2007). Estas estratégias de estudo representam a oportunidade de integrar o conhecimento construído por uma população local, ao conhecimento acadêmico sobre fenômenos e processos naturais. Estes registros sobre o conhecimento ecológico, também possuem um importante papel no resgate e valorização da cultura local (Melo; Lacerda; Hanazaki, 2008).

Contudo, a maioria das pesquisas etnodirigidas apresentam como foco do trabalho a relação da diversidade de plantas, com as enfermidades tratadas. Pouco é descrito acerca dos fatores sociais relacionados aos indivíduos que realizam benzimentos, bem como, a outros agentes da medicina popular. Além disso, o conhecimento científico deve agregar os elementos da realidade local, mesmo os mais simples e considerados "irrelevantes". Consequentemente, é necessária uma análise mais ampla, que possibilite verificar para além da biodiversidade e o uso de plantas bioativas. Isto porque, as diferenças nos fatores históricos, culturais, ecológicos e psicológicos podem ser preditores socioeconômicos, e se manifestam no processo de saúde-doença ( Zeni et al., 2017; Sousa; De Medeiros; Albuquerque, 2019).

O histórico do município de Guatambu (SC), remonta à colonização europeia de famílias advindas do Rio Grande do Sul, por volta do ano de 1910. Ou seja, pequenas famílias de agricultores que realizavam a extração da madeira por meio de companhias madeireiras do Brasil e de outros países. Assim, o Rio Uruguai sempre foi o principal condutor de comércio para a Argentina, sendo o responsável pelo intenso tráfego de balsas nos anos de 1940 a 1960. Dessa forma, nesta região, se observa desde sua criação uma grande miscigenação étnica e cultural, o que movimentou os gestores a procurarem parcerias visando a conservação e valorização das práticas populares de cura (Guatambu, 2020).

Nesse contexto, ao propor uma interação entre o conhecimento científico e o saber popular, essa pesquisa objetivou realizar um resgate cultural, bem como, identificar e caracterizar por meio de levantamento socioeconômico, os benzedores que utilizam de plantas medicinais no município de Guatambu (SC).

\section{Metodologia}

A pesquisa de campo foi realizada no município de Guatambu, situado na mesorregião Oeste de Santa Catarina. Com estimativa populacional de 4.692 habitantes (IBGE, 2021), esta localidade conta com 16 comunidades rurais, além da área urbana (Figura 1).

Este estudo é classificado como analítico, de natureza transversal, com abordagem quantitativa. Estudos analíticos objetivam avaliar eventos ou ocorrências considerando, as características das amostras ou populações (Lima, 2011). Estudos classificados como transversais ou seccionais, buscam avaliar se a exposição ao fator ou causa está presente ao efeito, no mesmo instante ou intervalo de tempo analisado (Thomas; Nelson; Silverman, 2007). Já as pesquisas quantitativas, descrevem resultados precisos, exatos, possibilitando segurança quanto às interferências estatísticas (Michel, 2009).

Para tanto, foi utilizado um questionário semiestruturado que guiou a investigação de campo. Este instrumento foi composto de questões abertas e fechadas, permitindo posteriormente a análise e compreensão de questões subjetivas, bem como, a quantificação de questões objetivas. A pesquisa foi aprovada no Comitê de Ética em Pesquisa envolvendo seres humanos, da Universidade Comunitária da Região de Chapecó (CEP-Unochapecó, número parecer: 3.771.699). 
Figura 1. Mapa do Brasil com destaque para a localização do estado de Santa Catarina e o município de Guatambu no Oeste do estado.

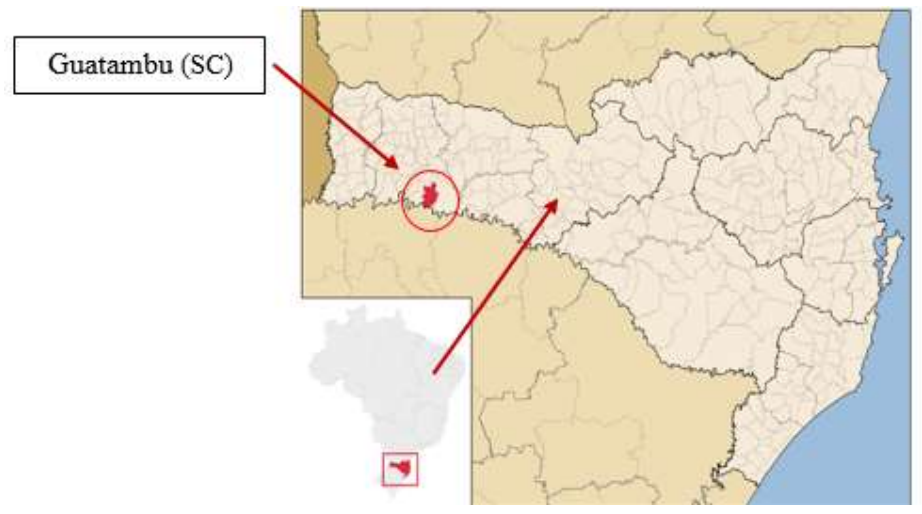

Fonte: https://en.m.wikipedia.org/wiki/Guatambu.

Para a seleção dos participantes foi determinado como critérios de inclusão, homens e mulheres residentes no município de Guatambu (SC), no perímetro urbano e rural, com idade de 18 a 90 anos. Estes participantes deveriam realizar práticas populares de cura (benzimentos) associadas à indicação de preparados à base de plantas medicinais.

Ainda na etapa de seleção de participantes, foi utilizada a técnica de snowball sampling conhecida popularmente como bola de neve. Por meio deste método, o pesquisador deve trabalhar com especialistas locais, deste modo, pessoas reconhecidas na comunidade como detentoras de conhecimento acerca do tema de pesquisa (Albuquerque, Alves, De Lucena, 2014). Didaticamente, cada participante recomendou outro membro, de forma que a amostra cresceu até atingir um ponto de saturação, ou seja, de repetição de indicadores (Gazzaneo; De Lucena; Albuquerque, 2005).

Nesse contexto, a aplicação do questionário semiestruturado possibilitou a identificação dos benzedores e possibilitou o levantamento de informações acerca de dados socioeconômicos destes agentes populares de cura. Foram contempladas questões na qual se buscou elementos sobre o sexo dos participantes, idade, ocupação, religião, participação em grupos sociais bem como aspectos relacionados à renda e constituição familiar.

\section{Resultados e Discussão}

A medicina popular se manifesta, principalmente, em duas áreas diferentes e que por vezes se complementam: a medicina caseira, baseada principalmente na utilização de preparados a partir de plantas medicinais e a medicina religiosa fundamentada principalmente na prática do benzimento (Queiroz; Carrasco, 1995). A medicina religiosa é uma área extremamente importante e complexa no contexto das práticas populares de cura. Esta, a exemplo da medicina clássica ocidental, tem seus próprios agentes como, os curandores, rezadores, benzedores que são procurados para restaurar a saúde das pessoas que a ela recorrem. O benzimento nestes casos, consiste na realização de uma oração com o objetivo de proteger e manter a saúde e o equilíbrio emocional de quem busca este tipo de recurso (Chagas et al., 2007).

Nesta pesquisa, a partir da técnica de snowball sampling, e tendo como ponto de partida a Secretária de Cultura do município, foram identificados 41 participantes da pesquisa. Contudo, somente 36 benzedores concordaram em participar deste trabalho.

Quanto à localização, 12 participantes (benzedores) declararam residir no perímetro urbano, os demais (24) estão distribuídos nas diversas localidades do município. Este dado demonstra, uma maior proporção de agentes populares de cura, nas regiões interioranas do município pois, durante muito tempo a medicina popular foi a única alternativa de cuidados a saúde para algumas populações distantes geográfica e socialmente dos centros urbanos. Especificamente, a prática de benzimentos 
sobrevive em diferentes espaços geográficos, como é o caso, em regiões mais afastadas, interioranas e nas periferias das grandes cidades, muitas vezes, com dificuldade de acessarem os serviços de atenção primária a saúde (Hoffmann-Horochovski, 2015). Como resultado, os curandores e benzedores nessas comunidades são muito valorizados e respeitados, exercendo papel de conselheiros em questões que vão desde a perda de objetos pessoais, dificuldades do matrimônio, dificuldades financeiras e, claro, problemas de saúde e espirituais (Marin; Scorsolini-Comin, 2017).

Foi observada a maior participação de 26 mulheres (72\%) em relação aos 10 homens (28\%), o que remete a concluir que a prática popular de cura conhecida como benzedeira ou curandor, envolve saberes tradicionais realizados principalmente, mas não exclusivamente, por mulheres, que assumem esta atividade como uma vocação. Este achado está de acordo com um estudo similar realizado em Ascurra (SC) que avaliou 42 participantes residentes nas comunidades rurais e urbanas, revelando que $85,7 \%$ dos entrevistados foram do sexo feminino e 14,3\% do sexo masculino (Meyer; Quadros; Zeni, 2012). Este fato nos remete a um contexto histórico-cultural em relação ao papel feminino. Onde a mulher assume a função de cuidar da casa, da alimentação e da saúde da família, possibilitando um ocupar um lugar de destaque na sistematização de conhecimentos bem como, manejo de plantas medicinais e alimentares (Prado, 2014).

Outro dado interessante, é que os benzimentos são realizados por pessoas idosas, estando na faixa etária dos 61 aos 70 anos (51\%) e 71 a 80 anos (29\%) (Figura 2). Isso pode ser justificado em parte, devido à dificuldade de coletar informações etnobotânicas com indivíduos jovens; da reduzida inclinação deste público para se relacionar com o meio ambiente e com as pessoas idosas, bem como, um descomprometimento em preservar o conhecimento tradicional e cultural. Os jovens são aparentemente menos motivados para aprender a utilizar os remédios à base de plantas e as práticas de cura em comparação aos idosos. Ou seja, com a modernização tecnológica, a cultura popular dos benzimentos e das plantas medicinais tem sofrido fortes interferências, entre elas, a desvalorização da cultura local, talvez, em virtude de uma maior exposição à sociedade urbana (Meyer; Quadros; Zeni, 2012; Perna; Lamano-Ferreira, 2013).

Acredita-se que a prática do benzimento por meio do uso de ervas e chás medicinais, ocorra dentre outros fatores, devido à simplicidade do preparo, associada ao tipo de tratamento não convencional que ela confere, aliado ao conhecimento tradicional repassado por gerações (Assunção; Querino; Rodrigues, 2020).

Figura 2. Idade dos benzedores no município de Guatambu (SC), 2020.

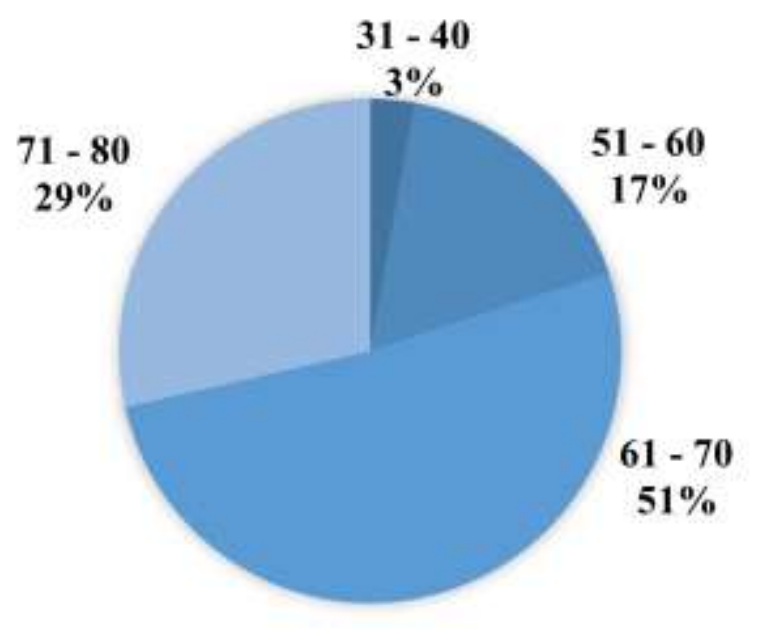

Nota: Entre 41 anos a 50 anos, não obtivemos participantes. Fonte: Autores.

Também foi verificado que os benzedores (agentes populares de cura) apresentam pouca escolaridade, porém, demonstram muito conhecimento adquirido ao longo de sua vida. Os dados revelaram que as escolaridades variaram desde um 
participante analfabeto $(1 ; 3 \%)$, alfabetizado $(4 ; 11 \%)$, ensino fundamental - primário completo $(19 ; 53 \%)$, ensino fundamental completo $(5 ; 14 \%)$, ensino médio completo $(4 ; 11 \%)$, ensino superior $(2 ; 5 \%)$, até um agente que possui pós-graduação (1; 3\%). Portanto, esse conhecimento tradicional resiliente, que segundo a maioria dos participantes é repassado por gerações, independe do grau de instrução, inserindo-se num processo prestigiado, mantendo-se vivo e reconhecido, mesmo diante das transformações tecnológicas advindas da atualidade. Assim, esse aprendizado independente do seu conhecimento escolar, pode ser dado a uma pessoa com elevado grau de instrução assim como, a uma analfabeta (Silva, 2018).

Quando questionados sobre a participação em grupos sociais, nove participantes relataram não frequentar nenhum grupo. Vale reforçar que se trata de uma prática que se contextualiza social e culturalmente, sendo muito influenciada por familiares e/ou grupos sociais (Soares et al., 2014). Salienta-se que muitas ocasiões, devido a situação da pandemia Covid-19, os participantes esqueceram das suas inclusões em seus grupos sociais, necessitando por vezes, pensar e elaborar uma resposta, relatando "[...] tinha antigamente, agora não tem mais". Sendo que a interrupção é temporariamente proveniente do isolamento social, referindo a uma situação não somente local, mas sim, uma pandemia mundial. Assim, não se fez a consideração da extinção dos grupos, ou da não estimulação do convívio social em comunidade. Mas, se ponderou os grupos citados. Os demais (27 benzedores) relataram frequentar mais que um grupo social, entre eles, se faz referência de citação aos grupos na Unidade Básica de Saúde (hipertensos e diabéticos - 1), grupo de idosos (4), cooperativas (5), grupos da igreja (13), pastoral saúde (4), pastoral criança (2), clube de mães (10), e o grupo sala da avó (2). Este último, incentivado pela Secretaria Municipal da Cultura.

Quanto ao estado civil dos participantes, 27 são casados (75\%), oito viúvos (22\%), e um divorciado (3\%). Destes, 17 (50\%) residem com seus cônjuges, 16 (47\%) residem além do cônjuge, com seus filhos e netos, e somente 3 (3\%) participantes residem sozinhos. Com relação a profissão/ocupação, observou-se a predominância de agricultores $(17 ; 47 \%)$, aposentados (6; $17 \%)$, do lar $(5 ; 14 \%)$, professor $(3 ; 8 \%)$, terapeuta holístico $(2 ; 5 \%)$, doméstica/diarista $(2 ; 6 \%)$, servente escolar $(1 ; 3 \%)$. Dados semelhantes foram obtidos no município de Ascurra (SC), em que as profissões que tiveram maior destaque entre os entrevistados foram a de afazeres domésticos e agricultores. Segundo Meyer et al. (2012) isto pode ser justificando devido aos agricultores terem maior contato com as plantas, manuseando-as com naturalidade. Bem como, os afazeres domésticos ou do lar, estariam com "maior tempo" para se dedicarem a este ofício.

Ao longo da aplicação do questionário semiestruturado, foi notado também, que as práticas de benzimentos estão relacionadas às questões religiosas. Assim, o benzimento e o uso das plantas medicinais foram se institucionalizando num contexto religioso, histórico e geográfico. Fatores importantes para a manutenção e contribuição no ato de minimizar as dificuldades encontradas pelos moradores para preservar a saúde (Silva, 2013). Nesse contexto, ao considerar o quesito religião/religiosidade, obteve-se 32 participantes que se declararam católicos (88\%), três evangélicos (9\%), e um espírita (3\%). Ou seja, ocorreu a predominância do catolicismo nos agentes populares de cura, assim como, em estudo similar realizado no litoral paranaense, que investigou a associação do catolicismo popular com a finalidade de curar doenças provenientes do corpo e do espírito. O caráter sagrado desta prática geralmente pode ser evidenciado no próprio ambiente de benzimento. Assim, nos locais da realização destas práticas populares, é comum a contemplação de imagens sacras e estatuetas de santos protetores do catolicismo popular, que são evocados de acordo com os males a serem tratados. Contudo, a forma de professar a oração, os gestuais e as recomendações variam de acordo com cada benzedeira ou curandor, e independem de religião (Hoffmann-Horochovski, 2015).

Os participantes que seguem a crença evangélica reafirmam que a igreja não apoia o benzimento, mas, seguem com o ato de orar, pois não é algo ruim. Um dos entrevistados declarou que: “[...] a igreja condena como pecado. O benzimento é um ensinamento passado pelo pai, pela mãe, é de Deus, e está na família há muito tempo”. Um estudo realizado nas cidades de Matinhos e Guaratuba, situadas no litoral paranaense, descreveu como obstáculo a prática popular de cura, a resistência das 
religiões evangélicas. O benzimento tem sido condenado por algumas religiões que questionam sua eficácia, bem como, o uso de imagens ou a evocação dos santos. É frequente, relatos tanto sobre pessoas que deixaram de benzer após terem se convertido, quanto sobre as que vão receber e dar benzimentos escondidas da família. A razão de fundo é a mesma: a prática não condiz com a fé evangélica (Hoffmann-Horochovski, 2015).

As orações agem em busca do alívio para as ansiedades e curas, tanto do corpo físico, como da alma. A prática do benzimento se resume em um ato de fé, que está intimamente relacionado à religião. Mas, isso não significa que esteja vinculada exclusivamente ao catolicismo, pois, o modo como cada benzedor encaminha o ritual de bênção revela além da formação religiosa, também a sua visão de mundo. Portanto, adornos, imagens de santos populares, rosário, evangelho kardecista, bíblia, símbolos das religiões afro-brasileiras, muitas das vezes ocupam o mesmo espaço. Cabe interpretar que as crenças levam a diversos caminhos e estes por sua vez conduzem para um mesmo fim: a busca de soluções para as angústias e a cura de males espirituais, físicos, sociais e até mesmo econômicos (Santos, 2016).

É de concordância que a religiosidade brasileira, desde os tempos coloniais, revelou-se impregnada de sincretismo, ou seja, diversas culturas de povos que aqui chegaram, com diferentes crenças, porém que buscam o mesmo propósito. Como consequência, a prática do benzimento era prioritariamente católica, o que restringia o local da prática às igrejas e santuários. Recentemente, religiões como a umbanda, o candomblé, os pentecostais e o kardecismo começaram a multiplicar as possibilidades de rituais curativos (Santos, 2016; Azevedo, 2017; Marin; Scorsolini-Comin, 2017; Silva, 2018).

Ao verificar o tempo que exercem a ocupação de agentes populares de cura, ou seja, há quantos anos são benzedores, foi observado que a maioria dos entrevistados realiza estas atividades por um período de 21 a 30 anos (Tabela 1). É notório, que o trabalho desenvolvido nas comunidades é praticamente de uma vida em doação ao próximo, prevalecendo o conhecimento empírico transmitido por meio da oralidade.

Tabela 1. Análise do tempo (anos) que os participantes exercem a atividade como benzedor no município de Guatambu (SC), 2020.

\begin{tabular}{l|c|c}
\hline Anos como benzedor & $\begin{array}{c}\text { Quantidade de participantes que } \\
\text { responderam à questão }\end{array}$ & $\%$ \\
\hline 10 a 20 & 8 & 26 \\
21 a 30 & 10 & 32 \\
31 a 40 & 9 & 29 \\
\hline 1 a 50 & 3 & 10 \\
\hline Acima de 51 & 1 & 3 \\
\hline
\end{tabular}

Fonte: Autores.

Didaticamente, foi compreendido que a procura das práticas populares de cura, como os benzimentos, ocorre numa tradição familiar, em que considera o benzedor como alguém com experiência de vida, que percebe a doença como um todo, isto significa, também seus aspectos sociais, culturais e psicológicos (Soares et al., 2014). Assim, uma das características de benzedeira ou curandor, é que muitas vezes não são capazes de explicar o motivo ou justificativa para suas práticas, alegando que, "[...] sei porque me ensinaram assim" ou "foi assim que eu aprendi", o que revela, que os aprendizados se sustentam na transmissão oral dos conhecimentos (Marin; Scorsolini-Comin, 2017).

Ao serem questionados sobre como denominam os benzimentos e para quais enfermidades servem como tratamento, foi percebido que os agentes praticam, em sua maioria, mais que um benzimento para tratar diversas doenças. Entretanto, como pode ser observado na Tabela 2, se destacam os benzimentos para rendidura e/ou machucadura. As quais podem ser comuns em indivíduos que exercem atividades laborais braçais, como por exemplo, trabalho como agricultor, indústrias, laticínios e frigoríferos. 
Tabela 2. Descrição dos benzimentos realizados por benzedores em Guatambu (SC) e a respectivas indicações de tratamento, 2020 .

\begin{tabular}{|c|c|c|c|}
\hline Benzimento & Tratamento & Respondentes & $\%$ \\
\hline Rendidura, machucadura & Distensões musculares & 25 & 15 \\
\hline Bicha & Verminose & 22 & 14 \\
\hline Tirar sol/ar & Cefaleia & 20 & 12 \\
\hline Cobreiro & Lesões de pele, erisipela & 14 & 9 \\
\hline Mau olhado & Inveja & 12 & 7 \\
\hline Amarelão & Anemia & 12 & 7 \\
\hline Quebrante & Inveja no bebê & 10 & 6 \\
\hline Mordida bicho & Mordida e picada de animais & 9 & 6 \\
\hline Susto & Criança chorosa & 8 & 5 \\
\hline Costela ou espinha aberta & Distensão muscular no bebê & 5 & 3 \\
\hline Estancar sangue & Hemorragia & 4 & 2 \\
\hline Sequério & Roubo ou objetos perdidos & 4 & 2 \\
\hline Ataque dos nervos & Irritabilidade & 4 & 2 \\
\hline Umbigo rendido & Cicatrização umbilical do bebê & 4 & 2 \\
\hline Míngua & Desnutrição & 3 & 2 \\
\hline Tormenta & Temporal, tempestade & 3 & 2 \\
\hline Queimadura & Doenças de pele & 2 & 2 \\
\hline Criação (animais) & Inveja na agricultura & 1 & 1 \\
\hline Recaída & Depressão pós-parto, puerpério & 1 & 1 \\
\hline
\end{tabular}

Fonte: Autores.

É importante enfatizar, que por vezes os entrevistados, forneceram respostas curtas, a fim de não especificar ou detalhar os benzimentos, temendo transmitir informações que poderiam os prejudicar como, "[...] transferir seus conhecimentos na hora errada". Estes dados estão de acordo com um estudo realizado por Marin e Scorsolini-Comin (2017) onde foi reiterada a preocupação em encontrar alguém que seja de confiança e que esteja realmente interessado em aprender e levar sua prática adiante com fidedignidade e dignidade. Uma vez que, juntamente com seus conhecimentos serão repassados seu nome, sua reputação, o trabalho de sua vida e, por extensão, sua própria identidade.

Ao analisarmos como foi adquirido o conhecimento de benzedor, foi constatado que estes saberes foram aprendidos principalmente por meio da oralidade, repassados entre os membros da família. Dos participantes da pesquisa, 13 citaram ter recebido o aprendizado da mãe (36\%), 5 (14\%) do pai e apenas 2 (6\%), citaram o aprendizado com indígenas. Ainda, 9 (25\%) descreveram ter recebido este dom de antigos benzedores (atualmente falecidos), alguns não souberam responder especificamente, pois o benzimento está na família a muito tempo, e vários membros repassam informações. É importante ressaltar que este tipo de conhecimento popular está ameaçado pela sua descontinuidade entre os jovens. Da amostra, 18 participantes relataram não terem ninguém da família para seguir com os ensinamentos e os que informaram continuidade, os aprendizes estão próximos do convívio familiar, sendo o esposo (a), nora e filha (o). Foi notada preocupação entre os participantes benzedeiros ao repassarem seus conhecimentos, pois, deve ocorrer uma escolha de seu sucessor.

Quando investigado qual o horário mais adequado para os benzimentos, os agentes revelaram que realizam suas práticas de cura em qualquer horário, mas preferem durante o dia, “[...] é melhor antes do sol cair, mas se alguém precisar a gente atende a noite. E criança é prioridade”. Quanto ao dia da semana, a maioria dos benzedores relataram que atendem todos os dias, com um tempo médio de duração de cinco a 10 minutos por benzimento, e que os usuários dos benzimentos, são crianças e adultos (Tabela 3 ). 
Tabela 3. Aspectos gerais relacionados as práticas de benzimento no município de Guatambu (SC), 2020.

\begin{tabular}{|c|c|c|c|c|c|c|c|}
\hline $\begin{array}{c}\text { Horário } \\
\text { adequado }\end{array}$ & $\mathbf{n}$ & $\begin{array}{l}\text { Dias da } \\
\text { semana }\end{array}$ & $\mathbf{n}$ & $\begin{array}{c}\text { Duração do } \\
\text { benzimento } \\
\text { (min) }\end{array}$ & $\mathbf{n}$ & $\begin{array}{c}\text { Benze quem? } \\
\text { Quem se } \\
\text { beneficia? }\end{array}$ & $\mathbf{n}$ \\
\hline $\begin{array}{l}\text { Durante o } \\
\text { dia, não a } \\
\text { noite }\end{array}$ & 9 & $\begin{array}{c}\text { Todos os } \\
\text { dias }\end{array}$ & 22 & 2 a 4 & 8 & Adultos & 3 \\
\hline $\begin{array}{l}\text { Qualquer } \\
\text { horário }\end{array}$ & 16 & $\begin{array}{c}2 \mathrm{x} \text { na } \\
\text { semana }\end{array}$ & 1 & 5 a 10 & 12 & Homem & 1 \\
\hline \multirow{4}{*}{$\begin{array}{c}\text { Menos } \\
\text { sábado, } \\
\text { domingo e } \\
\text { feriado santo }\end{array}$} & 6 & $\begin{array}{c}3 x \text { na } \\
\text { semana }\end{array}$ & 2 & 11 a 15 & 9 & Mulher & 2 \\
\hline & & $\begin{array}{c}\text { 4x na } \\
\text { semana }\end{array}$ & 1 & 20 & 2 & Criança & 7 \\
\hline & & $\begin{array}{c}\text { Menos } \\
\text { domingo }\end{array}$ & 3 & & & $\begin{array}{l}\text { Adultos e } \\
\text { crianças }\end{array}$ & 19 \\
\hline & & $\begin{array}{l}\text { Menos } \\
\text { final de } \\
\text { semana e } \\
\text { feriado } \\
\text { santo }\end{array}$ & 2 & & & & \\
\hline
\end{tabular}

Nota: $\mathrm{n}=$ número de respostas dos benzedores. Fonte: Autores.

Ao investigar sobre as práticas de cura e o uso das plantas medicinais, da nossa amostra total (36 participantes), 31 participantes utilizam das práticas populares de cura e plantas medicinais (os demais - cinco - somente benzem). Desse modo, quando perguntados sobre a possibilidade de ganho financeiro pelas práticas de cura (benzimento), dos 31 benzedores, 29 afirmaram não cobrar pela benção. Dois relataram a cobrança, já que segundo eles, tiveram investimentos em suas formações de benzedor (cursos e livros principalmente com as temáticas das PICs). Ao perguntar se os mesmos recebiam doações como contrapartida às práticas de cura, 10 (32\%) participantes responderam negativamente e $21(68 \%)$ acenaram de forma positiva. Estes descrevem receber dos usuários, "presentinhos ou lembrancinhas”, como por exemplo, alimentos, imagens de santos, roupas, itens para casa, entre outros agrados. Assim, segue a alusão de que a prática do benzimento é em sua maioria, realizada de maneira gratuita. Ou seja, a busca pela benção ou benzimento é uma herança cultural, a tradição e a eficácia relacionadas a estas atividades possui efeito em certas situações e enfermidades estando relacionadas a questões culturais que envolvem crença e fé transmitidas pelos antepassados (Assunção; Querino; Rodrigues, 2020). Em outras palavras, de acordo com relatos de entrevistados descrito por Santos (2016), o benzimento deve ser realizado sem custo para o usuário, visto que o oficiante recebe de Deus esse dom, não podendo cobrar qualquer valor. Em resumo, prevalece nessa prática milenar de cura com um caráter altruísta desprovido de remuneração.

Quando indagados sobre o local de aquisição das espécies das plantas, 16 participantes (53\%) apontaram o horto medicinal ou canteiro, sete (23\%) adquirem em suas propriedades, seis (20\%) no mato (planta nativa) e dois (4\%) adquire comercialmente. Estes relatos ressaltam a necessidade da manutenção do uso sustentável da biodiversidade, visto que o extrativismo pode levar a redução dos materiais vegetais utilizados, comprometendo o conhecimento e uso popular (Firmo et al., 2011). Vale reforçar, que o convívio familiar e os costumes construídos em volta do manuseio das plantas medicinais trazem referências dos motivos pela opção da utilização dos remédios à base de plantas. Isso se deve provavelmente, pela confiança nos produtos naturais e pelo conhecimento empírico adquirido com os mais idosos (Meyer; Quadros; Zeni, 2012). Em um estudo semelhante realizado no município de Videira (SC), o principal meio de obtenção das plantas medicinais utilizadas foi a partir de cultivo em casa (61\%) ou obtidas com vizinhos e parentes, confirmando que o cultivo doméstico é essencial para a preservação e transmissão do conhecimento etnobotânico (Silva; Bunchen, 2011). 
Quanto à forma de preparo (Figura 3), ocorreram algumas discrepâncias de nomenclatura entre os relatos dos participantes. Observaram-se dificuldade da diferenciação nos conceitos dos produtos quanto a sua produção, principalmente de xaropes e garrafadas. Isto porque, em algumas situações é produzido primeiramente o chá (extrato aquoso), e após a adição de mel ou açúcar até chegar no ponto de xarope. Outra questão foi que o simples fato de estocar as substâncias em garrafas, foi considerada uma preparação por garrafada. Contudo, as preparações do chá por decocção e infusão foram as mais representativas entre os benzedores.

Por fim, os benzedores que realizam preparados a partir de plantas medicinais, foram questionados sobre a possibilidade de proventos financeiros a partir dos seus produtos. Dos agentes avaliados, 24 (77\%) alegaram cobrar pelos remédios que produzem e sete não cobram (23\%). Ao indagar no que o auxílio financeiro colabora em sua renda, foi descrito que o valor é aplicado na aquisição das embalagens e etiquetas, amparo nas despesas da casa, como gás de cozinha e também, na compra de alguns ingredientes, como por exemplo, mel e cachaça. Este dado, diverge dos achados observados por Meyer et al. (2012) onde 78,9\% dos entrevistados posicionaram-se contra a prática de cobrança, pois, consideram que as plantas são dádivas divinas disponíveis a todos, e não é justo comercializá-las. Fica evidente que as práticas de populares de cura e o comércio em paralelo de plantas medicinais ou produtos obtidos a partir destas matérias-primas, pode variar de acordo com a região onde são exercidas estas ações, e talvez isto possa ser explicado em função do modus operandi tradicional ou quem sabe, por meio de capacitações realizadas ao longo do tempo.

Figura 3. Formas de preparo das plantas medicinais por benzedores no município de Guatambu (SC), 2020.

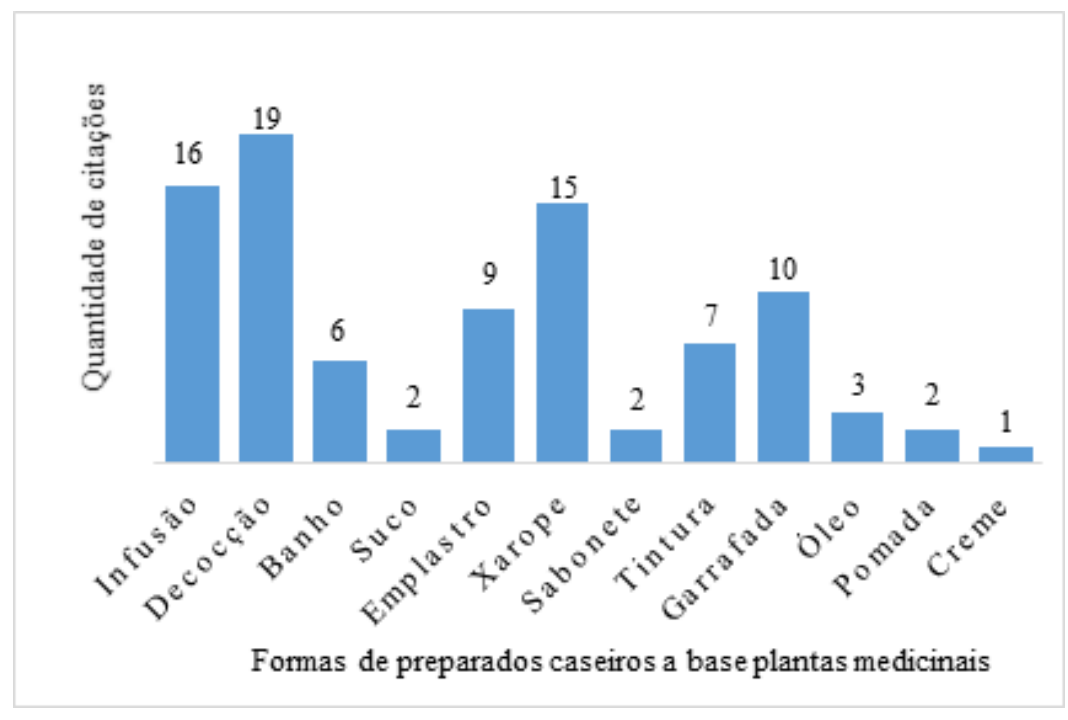

Fonte: Autores.

Ficou evidente nesta investigação que o benzimento e o uso de plantas medicinais são utilizados no tratamento de vários desconfortos psíquicos e físicos tanto na área urbana e rural do município e de que os agentes populares de cura (benzedores) promovem movimentação econômica na família e estão incrementando a preservação do meio ambiente. Este cuidado na valorização da cultura imaterial e principalmente a do saber popular instalado, é muito evidente entre as pessoas mais idosas da comunidade, principalmente nas mulheres. Nestas, residem os conhecimentos das antigas parteiras, receitas de remédios à base de plantas medicinais, rituais de oração e simpatia, e estão representadas como máxima expressão cultural do município, estando além de um compromisso religioso, mas, um compromisso com a vida, em se doar constantemente e continuamente ao próximo. Contudo, os participantes da pesquisa revelam muita preocupação para o aprendizado de jovens, já que está sendo cada vez mais escassa a transmissão desse conhecimento geracional. 


\section{Conclusão}

Os dados deste trabalho, contribuem para o resgate cultural de Guatambu (SC), por meio da identificação dos benzedores que realizam suas práticas com a preparação de produtos à base de plantas medicinais bem como, enfatiza seus aspectos socioeconômicos e culturais.

\section{Agradecimentos}

A Coordenação de Aperfeiçoamento de Pessoal de Nível Superior (Capes), Universidade Comunitária da Região de Chapecó (Unochapeco), Programa de Bolsas Universitárias de Santa Catarina (UNIEDU, Art. 170 e 171).

\section{Referências}

Albuquerque, U. P., Alves, R. R. N., De Lucena, R. F. P., \& Da Cunha, L. V. F. C. (2014). Methods and Techniques in Ethnobiology and Ethnoecology. Humana Press - Springer Sience 311-319.

Albuquerque, U. P., Silva, J. S., Campos, J. L. A, Souza, R. S., Silva, T. C., \& Alves, R. R. N. (2013). The current status of ethnobiological research in Latin America: Gaps and perspectives. Journal of Ethnobiology and Ethnomedicine, 9(1).

Assunção, L. M., Querino, R. A., \& Rodrigues, L. R. (2020). A benzedura nos territórios da Estratégia Saúde da Família: percepções de trabalhadores, usuários e benzedores. Saúde em Debate, 4(126), 762-773, 2020.

Azevedo, G. X. (2017). As benzedeiras na tecitura da cultura, religião e medicina populares. Tese de douturado em Ciências da Religião p. $13-17$.

Bunchen, J. A., \& Silva, M. (2011). Conhecimento etnobotânico sobre as plantas medicinais utilizadas pela comunidade do Bairro Cidade Alta , município de Videira, Santa Catarina, Brasil. Unoesc \& Ciência - ACBS, 2(2), 129-140.

Chagas, M. C. C., De Andrade, M. G., Da Costa, R. B., \& Perrelli, M. A. S. (2007). A prática de benzimento com uso de plantas na comunidade rural remanescente de quilombo de Furnas do Dionísio, Jaraguari, Mato Grosso do Sul The practice of blessings whith use of plants in the rural.

Firmo, W. C. A., Menezes, V. J. M., Passos, C. E. C., Dias, C. N., Alves, L. P. L., Dias, I. C. L., Neto, M. S., \& Olea, R. S. G. (2011). Contexto Histórico, uso popular e concepção científica sobre plantas medicinais. Caderno de pesquisa, 18, 2178-2229.

França, I., Souza, J. A., Baptista, R. S., \& Britto, V. R. S. (2007). Medicina popular: benefícios e malefícios das plantas medicinais. Revista Brasileira de Enfermagemv. 61, 201-208.

Gazzaneo, L. R. S., De Lucena, R. F., \& De Albuquerque, U. P. (2005). Knowledge and use of medicinal plants by local specialists in an region of Atlantic Forest in the state of Pernambuco (Northeastern Brazil). Journal of Ethnobiology and Ethnomedicine, 1, 1-8.

Gelesk, F. (2014). Benzedeiras na Ilha de Santa Catarina a partir da perspectiva de Oswaldo Rodrigues Cabral. Revista Santa Catarina em História, 8(1), 150160 .

Gewehr, R. B., Baêta, J., Gomes, E., \& Tavares, R. (2017). Sobre as práticas tradicionais de cura: subjetividade e objetivação nas propostas terapêuticas contemporâneas. Psicologia USP, 28(1), 33-43.

GUATAMBU, Município de Guatambu. (2020). <https://www.guatambu.sc.gov.br/>

Hoffmann-Horochovski, M. T. (2015). Benzeduras, garrafadas e costuras: considerações sobre a prática da benzeção. Guaju, 1(2), 110.

IBGE. Instituto Brasileiro de Geografia e Estatística. (2021). IBGE cidades. <https://cidades.ibge.gov.br/brasil/sc/guatambu>.

Lima, D. V. M. (2011). Desenho de pesquisa: uma contribuição para autores. Online Brazilian Journal of Nursing, 148, $148-162$.

Lima, R., Turrini, R., Silva, L. R., Melo, L., \& Augusto, S. I. (2017). Popular healing practices and medical plants use for riparian mothers in early childhood care. Revista de Pesquisa: Cuidado é Fundamental Online, 9(4), 1154, 2017.

Marin, R. C., \& Scorsolini-Comin, F. (2017). Desfazendo o "Mau-olhado": Magia, Saúde e Desenvolvimento no Ofício das Benzedeiras. Psicologia: Ciência e Profissão, 37(2), 446-460.

Melo, S., Lacerda, V. D., \& Hanazaki, N. (2008). Espécies de restinga conhecidas pela comunidade do Pântano do Sul, Florianópolis, Santa Catarina, Brasil. Rodriguésia, 59(4),799-812.

Mendes, D. S., \& Cavas, C. S. T. (2017). Benzedeiras e benzedeiros quilombolas - construindo identidades culturais. Interações, $19(1), 3-14$.

Meyer, L., Quadros, K. E.Q., \& Zeni, A. L. B. (2012). Etnobotânica na comunidade de Santa Bárbara. Revista Brasileira de Biociencias. 10(3), $258-266$.

Michel, M. H. (2009). Metodologia e pesquisa científica em ciências sociais: um guia prático para acompanhamento da disciplina.

Perna, T. A., \& Lamano-Ferreira, A. P. (2013). Revisão Bibliométrica Sobre o Cultivo de Plantas Medicinais em Quintais Urbanos em Diferentes Regiões do 
Research, Society and Development, v. 10, n. 13, e451101321538, 2021

(CC BY 4.0) | ISSN 2525-3409 | DOI: http://dx.doi.org/10.33448/rsd-v10i13.21538

Brasil ( 2009-2012 ) Bibliometric Revision on Cultivation of Medicinal Plants in Urban Backyards in Different Regions of Brazil ( $2009-2012$ ). Journal of Health, 61-68.

Prado, A. (2014). Estudo etnobotânico com vistas à sustentabilidade local do distrito de São. Dissertaçâo de Mestrado em Ecologia.

Queiroz, M., \& Carrasco, M. A. P. (1995). O Doente de Hanseníase em Campinas: Uma Perspectiva. People with Leprosy in Campinas, Brazil: An Anthropological Perspective. 11(3), 479-490.

Santos, L.G. (2016). A Inserção das Benzedeiras No Meio Popular ( Pires Do Rio E Palmelo ) a Inserção Das Benzedeiras No Meio Popular. Dissertaçâo de Mestrado em História.

Silva, C. M. da. O desaparecimento das plantas medicinais do cerrado: as implicações nas práticas de cura dos(as) raizeiros(as), benzedores(as), curandeiros(as) e pajés das comunidades indígenas Pankararu-Pataxó e Aranã. 2018. 76 f., il. Trabalho de Conclusão de Curso (Especialização em Sociobiodiversidade e Sustentabilidade no Cerrado)_Universidade de Brasília, Alto Paraíso de Goiás - GO, 2018

Silva, G. S. (2013). O significado cultural e religioso das benzeções: Prática e representações de benzedores de João Pinheiro. Journal of Chemical Information and Modeling, 53(9), 1689-1699.

Soares, A. N., Morgan, B. S., Santos, F. B. O., Matozinhos, F. P., \& Penna, C. M. M. (2014). Crenças e práticas de saúde no cotidiano de usuários da rede básica de saúde. Revista Enfermagem, 22(1), 83-88.

\&

Sousa, R.S., De Medeiros, P. M., Albuquerque, U. P. (2019). Can socioeconomic factors explain the local importance of culturally salient plants in a socialecological system? Acta Botanica Brasilica, 33(2),283-29.

Zeni, A. L. B., Parisotto, A. V., Mattos, G., \& Helena, E. T. S. (2017). Utilização de plantas medicinais como remédio caseiro na Atenção Primária em Blumenau, Santa Catarina, Brasil. Ciencia e Saude Coletiva, 22(8), 2703-2712. 